Louisiana State University

LSU Digital Commons

3-1-2014

\title{
Interannual variability of the Black Sea Proper oxygen and nutrients regime: The role of climatic and anthropogenic forcing
}

\author{
S. Pakhomova \\ P.P.Shirshov Institute of Oceanology, Russian Academy of Sciences \\ E. Vinogradova \\ P.P.Shirshov Institute of Oceanology, Russian Academy of Sciences \\ E. Yakushev \\ P.P.Shirshov Institute of Oceanology, Russian Academy of Sciences
}

A. Zatsepin

P.P.Shirshov Institute of Oceanology, Russian Academy of Sciences

G. Shtereva

Institute of Oceanology Bulgarian Academy of Sciences

See next page for additional authors

Follow this and additional works at: https://digitalcommons.Isu.edu/biosci_pubs

\section{Recommended Citation}

Pakhomova, S., Vinogradova, E., Yakushev, E., Zatsepin, A., Shtereva, G., Chasovnikov, V., \& Podymov, O. (2014). Interannual variability of the Black Sea Proper oxygen and nutrients regime: The role of climatic and anthropogenic forcing. Estuarine, Coastal and Shelf Science, 140, 134-145. https://doi.org/10.1016/ j.ecss.2013.10.006

This Article is brought to you for free and open access by the Department of Biological Sciences at LSU Digital Commons. It has been accepted for inclusion in Faculty Publications by an authorized administrator of LSU Digital Commons. For more information, please contact ir@lsu.edu. 


\section{Authors}

S. Pakhomova, E. Vinogradova, E. Yakushev, A. Zatsepin, G. Shtereva, V. Chasovnikov, and O. Podymov 


\title{
Interannual variability of the Black Sea Proper oxygen and nutrients regime: The role of climatic and anthropogenic forcing
}

\author{
S. Pakhomova a,*, E. Vinogradova ${ }^{a}$, E. Yakushev ${ }^{\mathrm{a}, \mathrm{b}}$, A. Zatsepin ${ }^{\mathrm{a}}$, G. Shtereva ${ }^{\mathrm{c}}$, \\ V. Chasovnikov ${ }^{\mathrm{d}}$, O. Podymov ${ }^{\mathrm{d}}$ \\ a P.P. Shirshov Institute of Oceanology RAS, Nakhimovski Prosp., 36, 117997 Moscow, Russia \\ ${ }^{\mathrm{b}}$ Norwegian Institute for Water Research, Gaustadalléen 21, NO-0349 Oslo, Norway \\ ${ }^{\mathrm{c}}$ F. Nansen Institute of Oceanology BAS, First May Street 40, P.O. Box 152, Varna 9000, Bulgaria \\ ${ }^{\mathrm{d}}$ The Southern Branch of the P.P. Shirshov Institute of Oceanology RAS, Golubaya bukhta, 353470 Gelendjik-7, Russia
}

\section{A R T I C L E I N F O}

\section{Article history:}

Received 8 November 2012

Accepted 8 October 2013

Available online 24 October 2013

\section{Keywords:}

dissolved oxygen

nutrient cycles

hydrogen sulphide

climatic changes

Black Sea

\begin{abstract}
A B S T R A C T
The Black Sea is a unique, stratified, enclosed ocean basin of great importance. The water column provides a wealth of information concerning aerobic-anaerobic biogeochemistry, the responses of which can have links to anthropogenic and climatic forcing. Herein, we synthesize dissolved oxygen (DO) and nutrient data (phosphate, dissolved inorganic nitrogen (DIN), and silicate) for the period 1984-2010 received in the northeastern and western areas of the Sea. In the subsequent analysis we discuss the role of anthropogenic and climatic forcing in the context of the Black Sea oxic layer and oxic/anoxic interface characteristics.

The DO concentration in the surface layer and in the Cold Intermediate Layer (CIL) decreased in warm periods and increased in cold periods, correlating to North Atlantic Oscillation (NAO) index variation. The biogeochemical regime of the Black Sea oxygenated upper layer has notably changed since 1999. After 1999 DO concentration in the CIL decreased by $20 \%$ while the concentrations in the surface layer changed very little. This provides evidence that the CIL waters were not fully replenished during the winters of the last decade.

The nutrient concentrations (DIN and phosphate) in the surface layer decreased significantly in the 2000 s compared with the 1980s-1990s. This decrease is regarded as improvement of the Black Sea ecosystem state. Oxygen and nutrient dynamics in the middle pycnocline have been decoupled since 1999. Presently physical (climatic) forcing is the dominant affecting factor controlling the Sea oxygen and nitrogen regime.
\end{abstract}

(C) 2013 Elsevier Ltd. All rights reserved.

\section{Introduction}

The Black Sea is a unique water body that contains the largest hydrogen sulphide-rich anoxic zone in the World Ocean. This Sea is a deep stratified anoxic basin that is almost completely enclosed. It is bound to the northeast by the Sea of Azov and to the southwest by the Sea of Marmara. The only significant shallow area is the Northwestern (NW) Shelf, which is about $20 \%$ by area and only $1 \%$ by volume (Fig. 1). In this relatively small area the largest Black Sea rivers represent $80 \%$ of the total freshwater input (Kosarev and Kostianoy, 2008). This paper focuses in the Black Sea "Proper" rather than bound by the Rim current frontal zone localized processes of the NW Shelf.

\footnotetext{
* Corresponding author.

E-mail address: s-pakhomova@yandex.ru (S. Pakhomova).
}

Over time, the vertical structure of the Black Sea has evolved to form a strong permanent stratification of the water column primarily due to high salinity waters entering the Black Sea through the Bosporus strait and low salinity riverine inputs. Additionally, the upper and deeper water masses are separated by a permanent halocline. Winter mixing results in the formation of an oxygen-rich Cold Intermediate Layer (CIL) positioned above the permanent halocline at depths lying between 50 and $120 \mathrm{~m}$. These surfaceorigin waters are characterized by a typical density of $\sigma_{\theta}=14.3-$ $14.7 \mathrm{~kg} \mathrm{~m}^{-3}$ and the rate at which CIL form varies in response to the intensity of winter cooling (Oguz et al., 2006; Oguz and Ediger, 2006; Kazmin et al., 2010).

The vertical diffusive flux of oxygen from the CIL is insufficient to meet the respirational consumption demands of degradation of sinking organic material. As a consequence, the strong vertical stratification results in a well oxygenated surface layer (from 0 to 


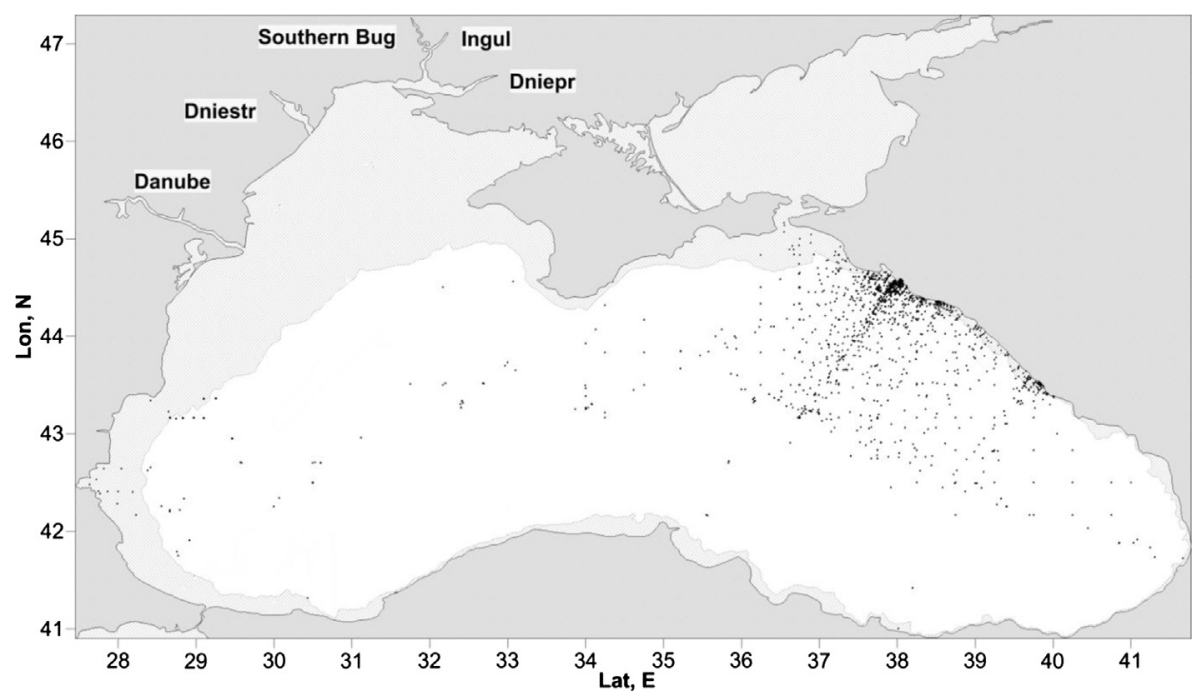

Fig. 1. Station locations in the Black Sea for period studied, 1984-2010 and principal river mouth positions. The areas shallower than $100 \mathrm{~m}$ are shaded.

50-200 m), a suboxic zone where the concentration of oxygen is below the detection limit of traditional methods applied (Murray et al., 1995), and a permanently anoxic deeper layer (from 70-200 to $>2000 \mathrm{~m}$ ) containing high sulphide concentrations (Sorokin, 2002).

The various oxidation-reduction reactions in the Black Sea water column and in particular those reactions that are typical of the suboxic zone occur in narrow layers of water of similar water density. These relate to the hydrochemical features (e.g., maxima and minima, onset points) that are characterized by the typical stable density levels (Vinogradov and Nalbandov, 1990; Murray et al., 1995; Volkov et al., 1997; Konovalov and Murray, 2001; Konovalov et al., 2005). Such a relationship provides a unique opportunity for data comparison and statistical analysis of data that is spatially variable (acquired in different regions of the Black Sea and during different sampling campaigns) and temporally variable due to seasonality.

The pelagic ecosystem dynamics of the Black Sea water column are determined by the climate-induced fluctuations and anthropogenic forcing, mainly related to eutrophication. Cold winter conditions typically correspond to increased nutrient conditions and phytoplankton biomass whilst mild winters correspond to decreased nutrient concentrations, and phytoplankton biomass (Oguz et al., 2006). The excessive nutrient enrichment of the Black Sea during the peak eutrophication period in 1970s-1980s was originally a result of enhanced riverine nutrient (silicate, nitrogen and phosphorus) supply into the northwestern shelf of the Sea. This subsequently led to accelerated growth and over-production of algae and opportunistic species of higher trophic levels, a high rate of oxygen utilization, the development of hypoxia or anoxia beneath productive areas, and the consequent degradation of benthic communities.

The total flux of nitrogen from the River Danube catchment area increased from $\sim 400$ kilotonnes $\mathrm{kt} \mathrm{y}^{-1}$ in the 1950 s to $900 \mathrm{kt} \mathrm{y}^{-1}$ in 1985-1990 (daNUbs, 2005). This flux was then reduced to $760 \mathrm{kt} \mathrm{y}^{-1}$ in 2000-2005. The flux of phosphorus was an order of magnitude smaller than nitrogen and increased from $40 \mathrm{kt} \mathrm{y}^{-1}$ in 1950 s to its peak value of $115 \mathrm{kt} \mathrm{y}^{-1}$ during the first half of the 1990 s. Subsequently this flux decreased to $70 \mathrm{kt} \mathrm{y}^{-1}$ in $2000-2005$. Both of these fluxes are thus approximately 1.5 times higher than the 1950s. The construction of the Iron Gate $1 \mathrm{dam}$ and reservoir in 1975 has been estimated to impose a minor influence on the total-N load, but was more apparent in controlling the total-P load
(daNUbs, 2005). Based on more recent measurements at the discharge point of the Sulina branch of the River Danube, this contribution was reduced to nearly $50 \%$ of the overall river-based dissolved inorganic nitrogen and phosphate loads (daNUbs, 2005; Oguz et al., 2008b) compared with 1970s -1980s.

The response of the Black Sea system to the above mentioned factors is being intensively studied to ensure proper nutrient management in the region and better knowledge on the possible impacts of climate changes (BSC, 2008; daNUbs, 2005); but there are still a lack of detailed estimates and descriptions of the Black Sea oxygen and nutrient regime dynamics. Responding to this deficiency, the present work focuses on the recent decadal changes of the oxygen, nutrient conditions and the position of the oxic/ anoxic boundary of the Black Sea using the Northeastern (NE) and Western (W) Black Sea as reference areas to base these studies on. The choice of these regions was determined by oxygen and nutrient reliable data availability, which reflect the Black Sea Proper (the Black Sea without the northwestern shelf region) nature.

The data from the NE Black Sea has a larger geographical coverage (from the Russian coast of the Black Sea to the center of the Black Sea Eastern Gyre) than for the W Black Sea and are available for a longer period (from 1980s). Furthermore the observations from the NE region are more important for a long period revealing changes. The upper layer chemical dynamics in the NE Black Sea reflect "integrated" rather than local changes of the Black Sea chemical parameters because influence of the Bosphorus and NW Shelf rivers is less significant when compared to the western and southern parts of the Sea (Yakushev et al., 2005). The NE Black Sea is characterized by the absence of a significant shelf, and the chemical characteristics of the near-coast and open sea water column are similar. In contrast, the $\mathrm{W}$ Black Sea region has a wide shallow area comprising coastal waters with depths down to $22 \mathrm{~m}$ and the shelf waters (60-100 m depth) extending to about $50 \mathrm{~km}$ offshore. Compared to the NE region, the W Black Sea is more sensitive to the influence of the northwestern (NW) shelf waters and river discharge forcing changes there.

The objective of this study is to analyze recent decade changes of the Black Sea oxygen and nutrient regime aiming to reveal a comparative role of climatic and anthropogenic factors in these changes. The results of this study will contribute to the estimates received for the 1970s-1990s (Konovalov and Murray, 2001; Konovalov et al., 2005; Yakushev et al., 2007a, b; Mikaelyan et al., 2013). 


\section{Data and methods}

The present study is based on data obtained from the NE and $\mathrm{W}$ Black Sea regions (Fig.1). Issues concerning the quality of the chemical data from databases (i.e. NATO-TU Black Sea, BSC) and systematic differences during measurement have complicated use, because different institutions and laboratories used varying techniques and different quality verifications standards. We based our work on the data collected by two organizations, 1980s-2010 data of the Shirshov Institute of Oceanology (SIO RAS, Moscow and Gelendzhik, Russia) and recent data (since 2000) from the Nansen Institute of Oceanology BAS (IO BAS, Varna, Bulgaria). These SIO RAS and IOBAS data were manually quality checked after each cruise. Both laboratories positively passed QUASIMEME tests and took part in an intercalibration cruise during the FP6 SESAME project. The most recent data were collected on cruises by these institutions as part of the SESAME project for the period 20072008. In this work the data collected in the open sea and shelf zones from both the NE and W Black Sea are used. The number of stations and samples used are given in Table 1.

In both regions dissolved oxygen (DO) was measured using the Winkler technique (Bordovskiy and Chernyakova, 1992; Hansen et al., 1999). The nutrient analyses for phosphate, silicate, nitrate, nitrite and ammonia were carried out using a segmented continuous-flow Techicon 11 autoanalyser or by photocolorimetric methods (Bordovskiy and Chernyakova, 1992; Grashoff et al., 1999).

The problem-oriented database "Verta" (PODB, Podymov, 2008) was used to calculate the statistical characteristics (i.e. average, minimum and maximum concentrations, standard deviation, etc.) of oxygen and nutrient distributions in the surface layer $(0-5 \mathrm{~m})$, the upper part of the CIL (at density values $\sigma_{\theta}=14.3-14.5 \mathrm{~kg} \mathrm{~m}^{-3}$ ), in the middle pycnocline $\left(\sigma_{\theta}=15.3-15.6 \mathrm{~kg} \mathrm{~m}^{-3}\right)$, oxygen deficient layer $\left(\sigma_{\theta}=15.75-15.85 \mathrm{~kg} \mathrm{~m}^{-3}\right)$ and to estimate the interannual variability of the hydrogen sulphide onset position. This PODB combines selected data and mathematical tools for their advanced processing and analysis, allowing effective quantitative analysis of spatial and temporal variability. For the DO seasonal variability estimations, the data collected in November-April were classified as winter data, and those collected in May-October as summer data.

\section{Results}

\subsection{Temperature}

Throughout the period of observations (1984-2010), the winter (January-March) mean sea surface temperature (SST) varied in the range of $6.4-9.5^{\circ} \mathrm{C}$, with a minimum in 1993 and maxima in 1999, 2001 and 2010 (Fig. 2a). Within the CIL of the NE Black Sea this inter-annual temperature variability is twofold lower than of the SST. The minimum temperature for the period 1984-2010 in the CIL was observed in $1993\left(6.7{ }^{\circ} \mathrm{C}\right)$ while maxima values were recorded in 2001 and 2010 ( 7.9 and $8.28{ }^{\circ} \mathrm{C}$, respectively). A clear increasing trend is observed in the CIL temperature since 1984 (Fig. 2a).

\subsection{Oxygen}

\subsubsection{Northeastern part of the Black Sea}

The general decadal trend of decrease of DO in the NE Black Sea revealed a negatively correlated pattern with the SST and the CIL temperature (Fig. 2). The range of DO concentrations in the surface layer was $280-350 \mu \mathrm{M}$ (95-107\% of saturation) in winter (Fig. 2b,c). Winter surface DO concentration decreased by about $20 \mu \mathrm{M}$ in the period 1984-2010. For the oxygen saturation, no trend was apparent during this period. Interannually DO in the CIL varied significantly with high values $(310-340 \mu \mathrm{M}, 80-95 \%$ of saturation) observed in the cold periods: 1990-1995 and 2004-2006, and low values (150-170 $\mu \mathrm{M}, 50-60 \%$ of saturation) recorded in the warm periods: 1984, 2000-2001, and 2009-2010. In the middle pycnocline $\left(\sigma_{\theta}=15.3-15.6 \mathrm{~kg} \mathrm{~m}^{-3}\right)$ and oxygen deficient layer $\left(\sigma_{\theta}=15.75-15.85 \mathrm{~kg} \mathrm{~m}^{-3}\right)$ the oxygen interannual variability followed a rather similar pattern to that in the CIL (Fig. 2d). In oxygen deficient layer DO concentration was about $12-23 \mu \mathrm{M}$ prior 1999

Table 1

Hydrochemical data collected by the SIO RAS and IO BAS in 1984-2010.

\begin{tabular}{|c|c|c|c|c|c|c|c|}
\hline \multirow[t]{2}{*}{ Year } & \multicolumn{7}{|c|}{ Number of stations/number of samples } \\
\hline & $\mathrm{O}_{2}$ & $\mathrm{PO}_{4}$ & $\mathrm{SiO}_{4}$ & $\mathrm{NO}_{2}$ & $\mathrm{NO}_{3}$ & $\mathrm{NH}_{4}$ & $\mathrm{H}_{2} \mathrm{~S}$ \\
\hline 1984 & $45 / 632$ & $42 / 621$ & $44 / 662$ & $33 / 512$ & $44 / 668$ & $5 / 81$ & $39 / 202$ \\
\hline 1986 & $5 / 66$ & $5 / 58$ & - & - & - & - & $3 / 12$ \\
\hline 1988 & - & $4 / 67$ & - & $2 / 29$ & $2 / 29$ & $3 / 52$ & $1 / 8$ \\
\hline 1989 & $237 / 2035$ & $211 / 1722$ & 215/1752 & $217 / 1750$ & $212 / 1711$ & $207 / 1861$ & $5 / 31$ \\
\hline 1990 & $62 / 446$ & $58 / 436$ & $58 / 435$ & $58 / 434$ & $58 / 325$ & $62 / 447$ & $27 / 135$ \\
\hline 1991 & $65 / 773$ & $65 / 765$ & $26 / 266$ & $62 / 751$ & $25 / 204$ & $37 / 372$ & $53 / 352$ \\
\hline 1993 & $17 / 245$ & $17 / 112$ & $17 / 154$ & $17 / 246$ & $17 / 129$ & $17 / 163$ & $17 / 153$ \\
\hline 1994 & $118 / 1069$ & $39 / 178$ & - & $28 / 138$ & $39 / 179$ & $101 / 919$ & $77 / 694$ \\
\hline 1995 & $31 / 355$ & $31 / 347$ & $31 / 347$ & $11 / 91$ & - & $20 / 176$ & $33 / 302$ \\
\hline 1996 & $94 / 742$ & - & - & - & - & - & $79 / 651$ \\
\hline 1997 & $31 / 298$ & $29 / 215$ & 26/137 & $31 / 247$ & - & $24 / 377$ & $26 / 312$ \\
\hline 1998 & 19/192 & - & - & $19 / 131$ & - & - & $16 / 82$ \\
\hline 1999 & $128 / 928$ & $118 / 1301$ & $123 / 1278$ & $45 / 238$ & $40 / 214$ & $127 / 1455$ & $100 / 788$ \\
\hline 2000 & $101 / 683$ & $101 / 959$ & $101 / 889$ & $93 / 780$ & $58 / 465$ & $84 / 851$ & $51 / 294$ \\
\hline 2001 & $146 / 1200$ & $110 / 1347$ & $108 / 1313$ & 93/894 & $89 / 808$ & $90 / 1124$ & $33 / 396$ \\
\hline 2002 & $117 / 679$ & $109 / 955$ & $107 / 949$ & $116 / 866$ & $69 / 375$ & $121 / 1024$ & $45 / 325$ \\
\hline 2003 & $16 / 135$ & $16 / 157$ & $16 / 157$ & $16 / 135$ & $16 / 135$ & $16 / 149$ & $16 / 99$ \\
\hline 2004 & $48 / 657$ & $54 / 827$ & $52 / 794$ & $52 / 728$ & $46 / 608$ & $48 / 746$ & $41 / 324$ \\
\hline 2005 & $55 / 538$ & $56 / 617$ & $56 / 609$ & $55 / 575$ & $47 / 468$ & $56 / 612$ & $35 / 213$ \\
\hline 2006 & $68 / 274$ & $67 / 279$ & $66 / 250$ & $66 / 246$ & $51 / 151$ & $67 / 282$ & $15 / 104$ \\
\hline 2007 & $97 / 455$ & $94 / 530$ & $94 / 529$ & $67 / 364$ & $65 / 293$ & $96 / 656$ & $21 / 231$ \\
\hline 2008 & $80 / 566$ & $81 / 721$ & $78 / 704$ & $81 / 667$ & $81 / 558$ & $78 / 568$ & $37 / 206$ \\
\hline 2009 & $99 / 284$ & $98 / 330$ & $98 / 324$ & $97 / 280$ & $97 / 268$ & $97 / 290$ & $27 / 170$ \\
\hline 2010 & $44 / 248$ & $44 / 258$ & $44 / 258$ & $44 / 242$ & $44 / 222$ & $44 / 254$ & $16 / 72$ \\
\hline Total & $1723 / 13,495$ & $1449 / 12,796$ & $1360 / 11,807$ & $1303 / 10,346$ & $1100 / 7812$ & $1415 / 12,459$ & $830 / 6156$ \\
\hline
\end{tabular}



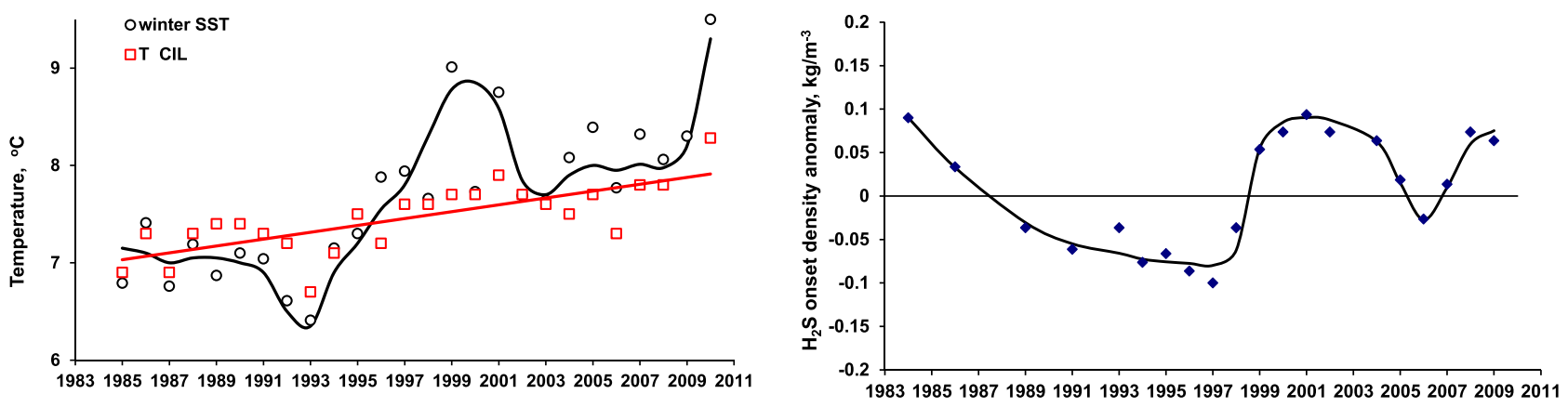

b
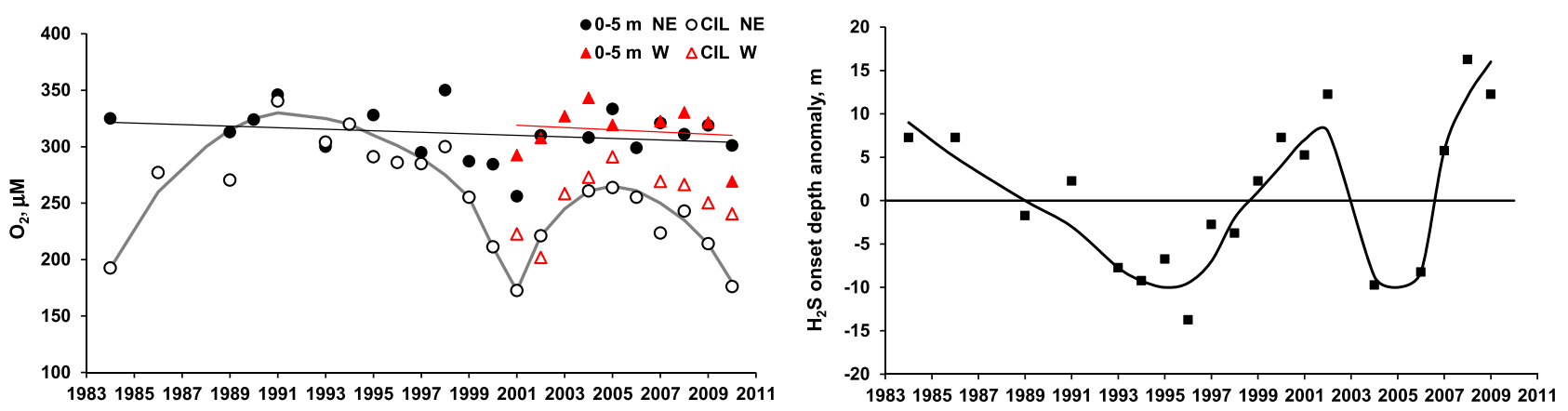

C
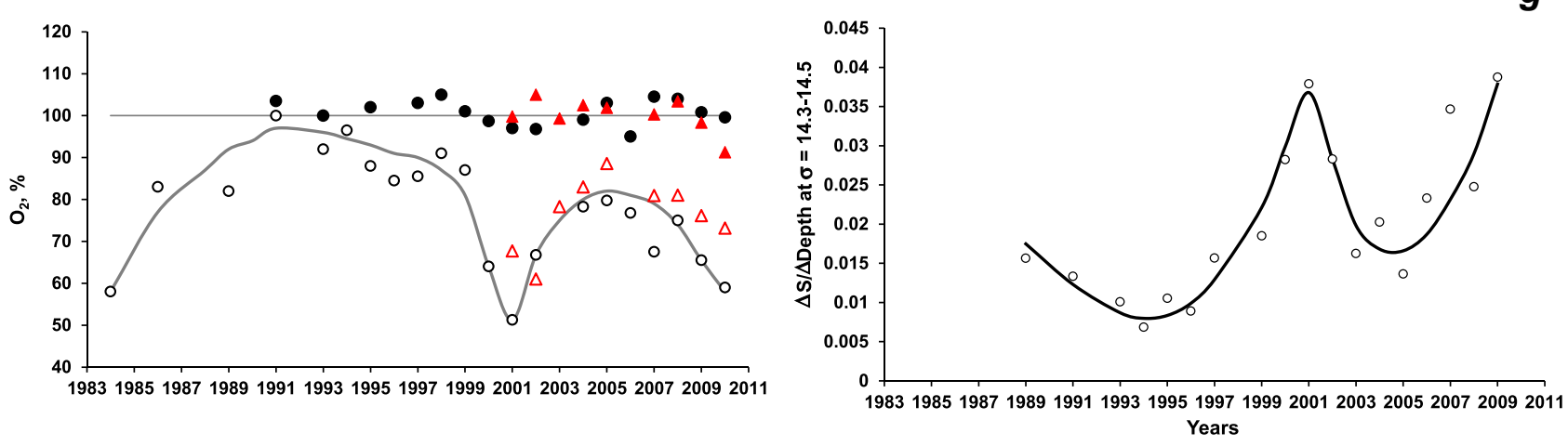

d

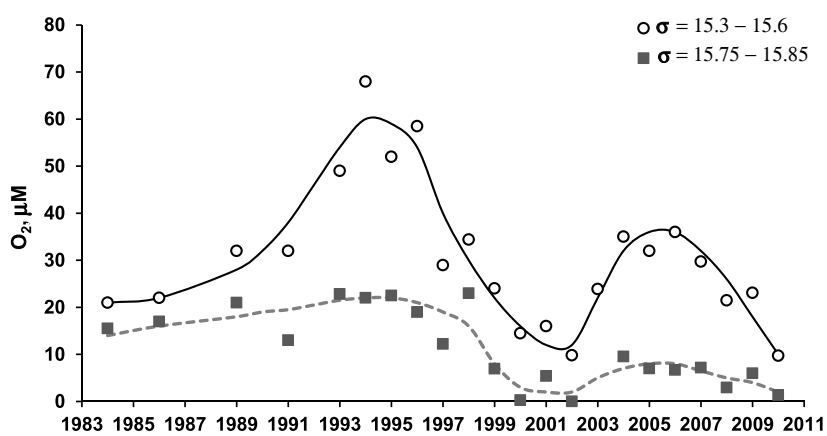

Years

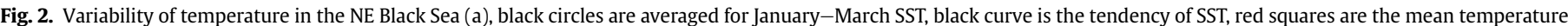

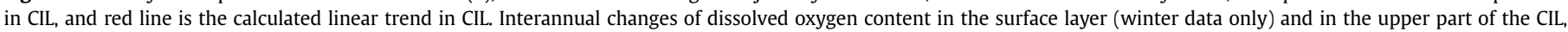

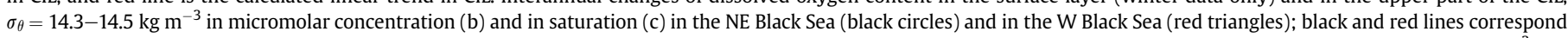

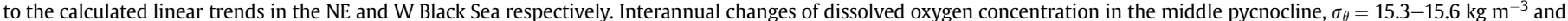

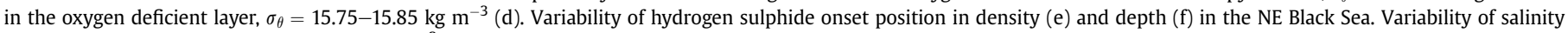

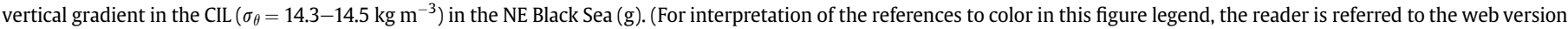
of this article.) 

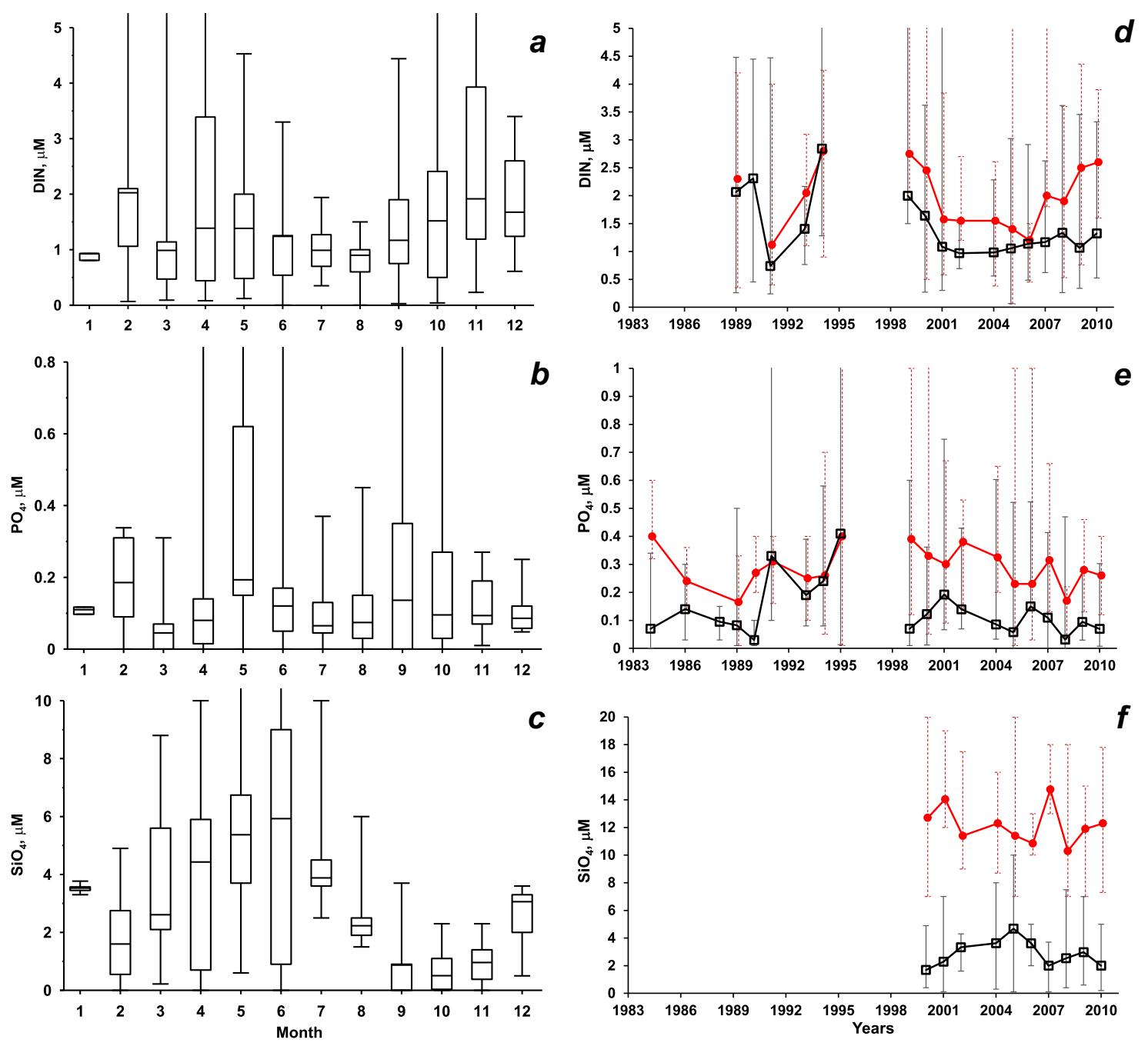

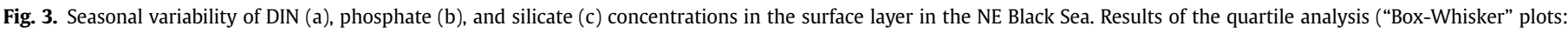

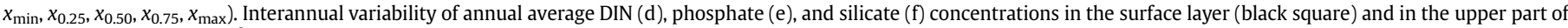

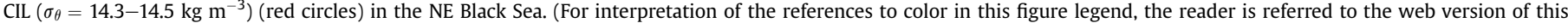
article.)

with maxima in 1993-1995 (the colder period of observation). Since $1999 \mathrm{DO}$ concentration has not exceeded $8 \mu \mathrm{M}$ and was close to zero in 2000, 2002 and 2010 (the warmer years).

\subsubsection{Western part of the Black Sea}

In the $\mathrm{W}$ Black Sea the winter surface layer DO concentration ranged in $2001-2010$ from 260 to $340 \mu \mathrm{M}$ (92-105\% of saturation) (Fig. 2b,c). The DO concentration of the surface layer has the same decreasing trend as in the NE part of the Sea and similarly no trend for the oxygen saturation was observed during this period. DO concentration in the CIL varied from 200 to $290 \mu \mathrm{M}$ (60-88\% of saturation) with maximum in 2005 and minima in 2001-2002 and 2010.

\subsection{Oxic/anoxic interface}

Results of calculations of the anoxic zone boundary position in the density field are shown in Fig. 2e. The values are slightly different from those reported by other authors who used visual or linear regression methods for estimating the hydrogen sulphide onset values (Murray et al., 1995; Volkov et al., 1997). Calculation of onset points of hydrogen sulphide was performed in the following way. Every station was analyzed individually. Top $200 \mathrm{~m}$ layer for every station was analyzed. At first, a spline was built using 4 or more top non-zero values of $\mathrm{H}_{2} \mathrm{~S}$. We used the Akima spline-based method (Akima, 1978) that provides better results than linear interpolation or other spline methods. In short, this method produces a less smooth curve than most other splines, but is stable regarding outliers. This is the disadvantage of cubic splines that can oscillate when including an outlier, while a more simple linear interpolation is too crude for the purposes of this study.

The second order adapted Adams method was used to extrapolate the created spline function into the upper layers. The calculated extrapolation value was added to the $\mathrm{H}_{2} \mathrm{~S}$ data and the spline was rebuilt. This procedure was repeated until the detection limit of hydrogen sulphide was reached. A complete description of the technique used is given in Podymov (2008).

The analysis indicate that the density level of hydrogen sulphide concentrations varied in the range of $\sigma_{\theta}=16.15-16.25 \mathrm{~kg} \mathrm{~m}^{-3}$ in 1991-1998. In 1999-2000, a significant upward shift in the boundary position of about $\sigma_{\theta}=0.05-0.20 \mathrm{~kg} \mathrm{~m}^{-3}$ was found (Fig. 2e). Since 2000, the hydrogen sulphide boundary position stabilized at a new level: $\sigma_{\theta}=16.10 \mathrm{~kg} \mathrm{~m}^{-3}$. The depth range of this boundary is about $10-30 \mathrm{~m}$ and it nearly coincides with the density variability (Fig. 2f). 


\subsection{Nutrients}

\subsubsection{Northeastern part of the Black Sea}

Seasonal and interannual variability of all nutrients in the NE Black Sea was characterized by significant irregular fluctuations for various time periods (Fig. 3). They were possibly connected with the influence of eddies, meteorological forcing, coastal discharge, biota, etc. that mask the seasonal and interannual signals. A difference in the nutrient concentration regime between the shelf waters and open sea NE region was not noticeable.

In 1989-2000, the concentration of dissolved inorganic nitrogen (DIN, a sum of nitrite, nitrate, and ammonia) in the surface layer in the NE Black Sea was characterized by the highest concentrations (maximum observed value $\approx 11 \mu \mathrm{M}$, annual average $\approx 2 \mu \mathrm{M}$, Fig. 3d). Since 2001, the maximal observed concentrations did not exceeded $2 \mu \mathrm{M}$, annual average was $1 \mu \mathrm{M}$. The years 20092010 were characterized by a very low level of DIN $(<1 \mu \mathrm{M})$. It was barely possible to distinguish the seasonal dynamics (Fig. 3a), yet minimal concentrations of DIN were observed in summer and maximal in winter season.

The surface layer phosphate concentrations were highest in the 1991-1995, annual average values reached $0.41 \mu \mathrm{M}$, maximum $2.6 \mu \mathrm{M}$ (Fig. 3e). Since 2000, the annual average concentration decreased to $0.1-0.2 \mu \mathrm{M}$, and the maximal observed concentrations have not exceeded $0.7 \mu \mathrm{M}$. Similar to DIN, the phosphate seasonal dynamics were not well expressed, while maximum concentrations were recorded in May and could drop down to zero in summer (Fig. 3b).

During 2000-2010, the silicate concentration had not shown any considerable change at the interannual scale (Fig. 3f). The highest concentrations were characterized for 2004-2006, 3.6$4.7 \mu \mathrm{M}$, the lowest - for 2000,2007 , and $2010, \approx 2 \mu \mathrm{M}$. The seasonal variations of silicate were more pronounced than those of the other nutrients (Fig. 3c). Minimum concentrations (0.5-1 $\mu \mathrm{M})$ were observed in late summer-autumn (August-November), while maximum concentrations $(5-8 \mu \mathrm{M})$ were registered in springsummer (April-June). The latter is related to the riverine supply of silicate which increases during periods of high water flows.

To reveal the nutrients interannual variability the data set requires filtration to remove the seasonal signal, which could be strong in certain areas and in turn masked by short-term fluctuations. According to the European Environment Agency (http:// www.eea.europa.eu/), the trends in winter nutrient concentration interannual dynamics should be regarded as an indicator of the marine environment eutrophication status. Lack of data for winter seasons constrains us to integrate three-year periods to estimate the real nutrient regime. For the NE Black Sea the interannual dynamics of the nutrient concentrations for the winter averaged data (Fig. $4 \mathrm{a}-\mathrm{c}$ ) and annual averaged data (Fig. 3d-f) practically coincide. The highest winter concentrations of DIN were found in the 1989-2001 period ( $>2 \mu \mathrm{M}$ ) followed by a remarkable decrease to about $1 \mu \mathrm{M}$ that remained till 2010. The phosphate winter interannual variability was characterized by high mean concentrations in 1993-1995 (about $0.5 \mu \mathrm{M}$ ) and very low concentrations $(<0.1 \mu \mathrm{M})$ from 2005 to 2010 . No trend was observed for silicate winter concentrations in the surface layer since 2000.

The phosphate and silicate concentrations in the upper part of the CIL showed no tendencies in the studied period (Fig. $3 e-f$ ). DIN variability in the CIL is very close to the one in the surface layer (Fig. 3e). The annual average nutrients concentrations in the CIL varied between $1.2-2.7 \mu \mathrm{M}, 0.17-0.39 \mu \mathrm{M}$, and $10.9-14.8 \mu \mathrm{M}$ for DIN, phosphate, and silicate respectively and were about $2-6$ times higher than those in the surface layer.

The annual average concentrations of nitrate in the upper part of pycnocline amounted to $7-8 \mu \mathrm{M}$ before 1993 followed by its
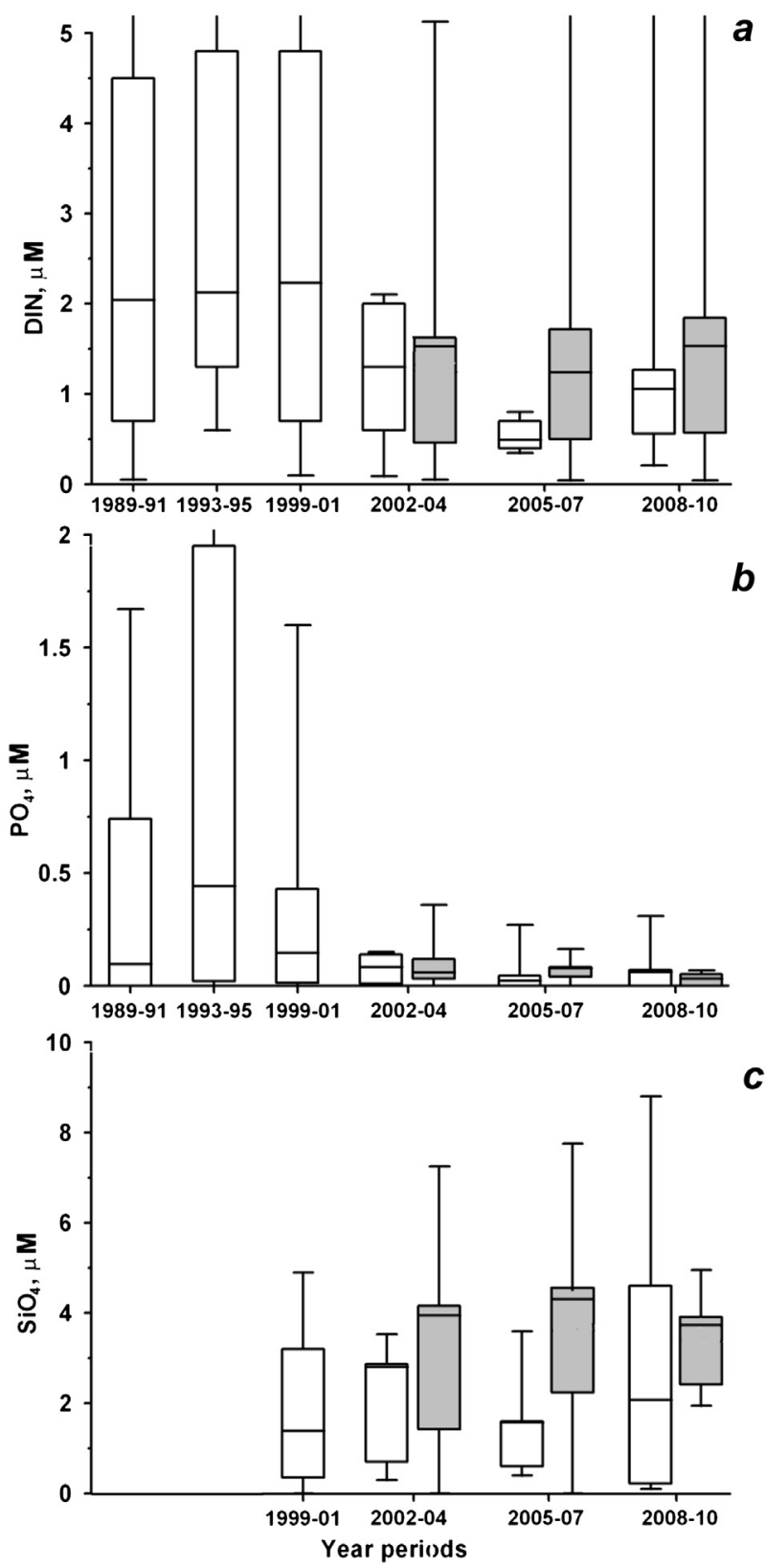

Fig. 4. Interannual winter variability of DIN, phosphate and silicate concentrations in the surface layer (a, b, c) averaged for 3 years in the NE Black Sea (white boxes) and W Black Sea (gray boxes).

Table 2

Averaged concentrations of nutrients and nutrient molar ratios in the W Black Sea for different seasons and years.

\begin{tabular}{llllllll}
\hline & & $\mathrm{DIN}$ & $\mathrm{PO}_{4}$ & $\mathrm{SiO}_{4}$ & $\mathrm{~N} / \mathrm{P}$ & $\mathrm{Si} / \mathrm{N}$ & $\mathrm{Si} / \mathrm{P}$ \\
\hline \multirow{2}{*}{$2001-2004$} & Winter & 1.55 & 0.06 & 3.94 & 26 & 2.5 & 66 \\
& Spring & 1.98 & 0.19 & 4.47 & 10 & 2.3 & 24 \\
& Summer & 1.82 & 0.08 & 3.26 & 23 & 1.8 & 41 \\
$2005-2007$ & Winter & 1.24 & 0.10 & 4.32 & 12 & 3.5 & 43 \\
& Spring & 1.05 & 0.06 & 3.98 & 17 & 3.8 & 66 \\
& Summer & 0.61 & 0.05 & 1.42 & 12 & 2.3 & 28 \\
& Winter & 1.53 & 0.05 & 3.77 & 31 & 2.5 & 75 \\
& Spring & 1.15 & 0.05 & 2.96 & 23 & 2.6 & 59 \\
& Summer & 1.51 & 0.08 & 2.01 & 19 & 1.3 & 25 \\
\hline
\end{tabular}


decrease down to $3-5 \mu \mathrm{M}$ in 1993 which remained at this level until 2010.

\subsubsection{Western part of the Black Sea}

In 2001-2010 the concentrations of all nutrients in the surface layer in the W Black Sea were the same as in the NE part with average values $1.4,0.08,3.3 \mu \mathrm{M}$ for DIN, phosphate and silicate respectively (Table 2). For the winter period the shelf and the open sea waters showed no clear trends in the surface layer nutrient average concentrations during the last decade (2001-2010), and were about $1.2-1.5,0.05-0.1$ and $3.8-4.3 \mu \mathrm{M}$ for DIN, phosphate and silicate respectively (Fig. $4 \mathrm{a}-\mathrm{c}$ ). For spring season clear decreasing trends were observed for phosphate and silicate (Table 2).

\subsubsection{Nutrient ratios}

In the NE Black Sea, the surface N/P ratio decreased from 25 in 1999-2000 to 5-10 in 2001-2008 (Fig. 5a), which was related to the decrease of the DIN concentration after 2000. For the last two
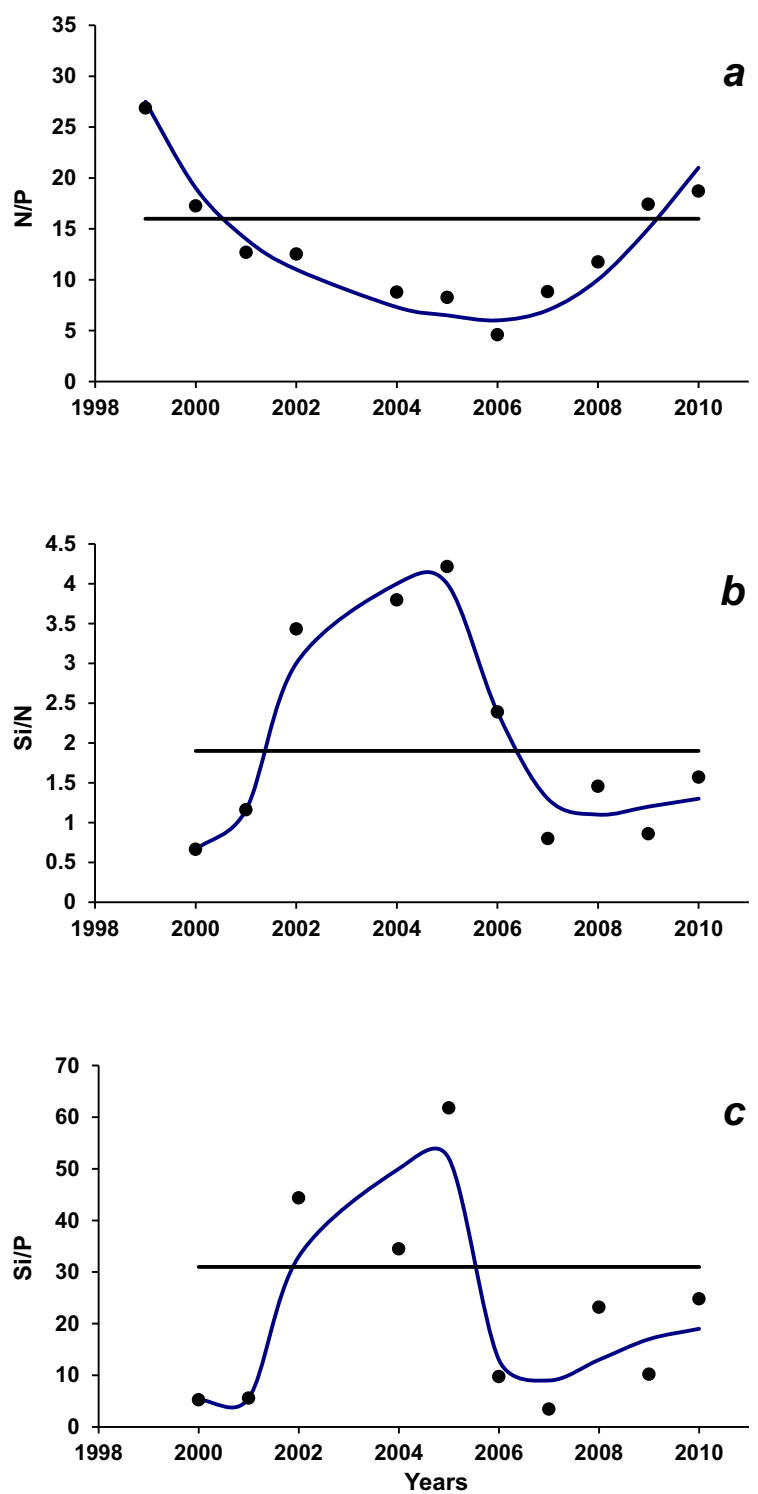

Fig. 5. Interannual variability of the $\mathrm{N} / \mathrm{P}(\mathrm{a}), \mathrm{Si} / \mathrm{N}(\mathrm{b})$ and $\mathrm{Si} / \mathrm{P}(\mathrm{c})$ molar ratios in the $\mathrm{NE}$ Black Sea. Horizontal lines show Redfield ratio values: $\mathrm{N} / \mathrm{P}=16, \mathrm{Si} / \mathrm{N}=1.9, \mathrm{Si} / \mathrm{P}=31$. years, 2009-2010, this ratio increased to more than 16 (Redfild's ratio) because of a very low concentration of phosphate in the surface layer with an almost constant DIN concentration after 2001. The Si/N and Si/P ratios show a silicate deficit up to 2002 and during 2006-2010 (Fig. 5b,c). The years 2002-2005 were characterized by higher values of both ratios due to a decrease in phosphate and DIN concentrations and an increase in silicate content.

In the $\mathrm{W}$ Black Sea, the N/P ratio also decreased to lower than Redfield's one (up to 12) in period 2005-2007 followed by its increase again to $20-30$ in 2008-2010 as it had been in 2001-2004 (Table 2). The $\mathrm{Si} / \mathrm{N}$ and $\mathrm{Si} / \mathrm{P}$ ratios show silicate excess for winter and spring seasons and its deficit for summer.

\section{Discussion}

The studies of the hydrophysical properties of the Black Sea (Piotukh et al., 2011) revealed that the entire deep-water part of the Sea features high spatial homogeneity. The data spatially averaged both over the whole deep water part of the Sea and over its four subregions (NE NW, SW and SE) considered in this paper ((Piotukh et al., 2011) can serve as integral indicators of the strength of atmospheric forcing. CIL properties are relatively uniform in the interior Black Sea (Ozsoy and Unluata, 1997). As presented above, the hydrochemical features (e.g., maxima and minima, onset points) are characterized by the typical stable density levels in all the Black Sea Proper (Vinogradov and Nalbandov, 1990; Murray et al., 1995; Volkov et al., 1997; Konovalov and Murray, 2001; Konovalov et al., 2005).

The results based on observations in the NE and W Black Sea can therefore be extended to the whole Black Sea Proper. As it will be shown in the following discussion the NE and $\mathrm{W}$ area characteristics are similar, but differ from those of the NW shelf region.

\subsection{Physical forcing and oxygen regime}

\subsubsection{Northeastern part of the Black Sea}

Temperature variations in the Black Sea appear to be governed by the North Atlantic Oscillation (NAO) and East Atlantic-West Russia (EAWR) teleconnection patterns, comprising various combinations of low and high surface pressure anomaly centers over the North Atlantic and Eurasia (Oguz et al., 2006). The NAO teleconnection to the Black Sea is opposite to that taking place in the eastern North Atlantic and its marginal seas. Relatively cold and dry winters occur during the positive phase of the NAO, and vice versa for the milder and wetter winters (Oguz et al., 2006). The connection between the NAO index and SST becomes better visible at values of the NAO index considerably different from zero (Kazmin and Zatsepin, 2007; Kazmin et al., 2010). The years 19891995 were characterized by a well pronounced positive NAO index that corresponded to the SST minimum period in the Black Sea (Figs. 2a and 6). Since 1996 the negative NAO index dominated with minima in 1998-1999 and 2010 resulted in corresponding SST maxima. In total the winter SST has shown a clear increasing trend since 1984. This corresponds to recent findings of Shapiro et al. (2010) that the deep Black Sea has been warming over the last $15-20$ years.

Our data set exhibits a linear warming trend with the CIL temperature rise of $0.5{ }^{\circ} \mathrm{C}$ during the last two decades (Fig. 2a) reflecting the global warming in the Black Sea region. This is consistent with the warming observed in winter over Eurasia, which can be explained, in part, by warm air advection from the North Atlantic region (i.e. connected to the NAO) (Oguz et al., 2006).

Since 1984, the winter surface layer DO concentrations have tended to decrease interannually (Fig. 2b), and that was correlated with the increasing temperature trend. Meanwhile, no trend was 


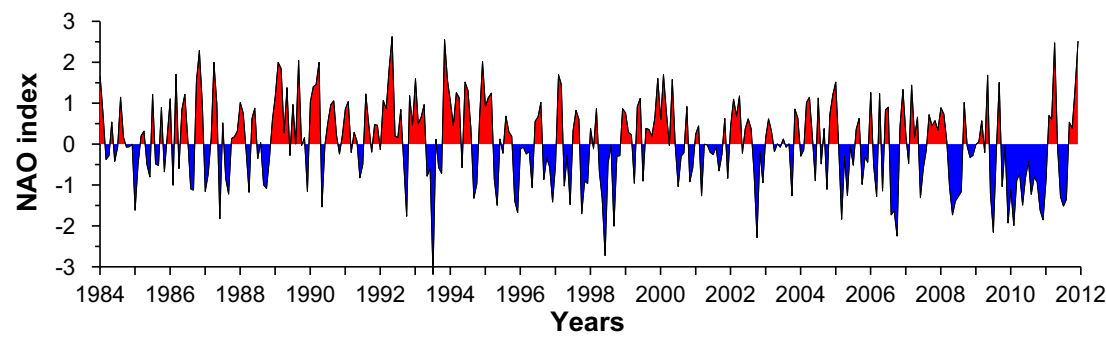

Fig. 6. North Atlantic oscillation index (http://www.cpc.ncep.noaa.gov).

observed for the oxygen saturation in the surface layer. The oxygen saturation was around $100 \pm 5 \%$ (Fig. 2c) that testifies that the winter surface oxygen content depends on temperature only.

The oscillations of DO in the CIL are connected with the winter weather conditions. DO can be supplied to the CIL during the winter mixing events, when the temperature (and density) distributions between the sea surface and the CIL core depth become uniform as observed during winter 2003 (Gregg and Yakushev, 2005). Such events are more typical for the winters with the colder SST and stormy weather. For instance, during the warm winters of 1999 and 2001 (the winter of 2000 was moderately cold) when both the SST and the temperature in the CIL core exhibit a remarkable increase (Fig. 2a) (Krivosheya et al., 2002; Oguz et al., 2006), the process of the oxygen-rich CIL formation was weaker compared with the years before and after. Consequently, DO concentrations decreased to the minimal values observed in 2000-2001 (170-210 $\mu \mathrm{M}, 50-60 \%$ of saturation, Fig. 2b,c). After the relatively cold winter of 2003, the oxygen content in CIL increased in 2004-2006 $(250-270 \mu \mathrm{M}$, about $80 \%$ of saturation) but did not reach the values observed in the early 1990s (280-340 $\mu \mathrm{M}, 90-95 \%)$.

While analyzing the interannual and interdecadal changes, one can see that before 1999, winter DO concentrations in the CIL corresponded to those in the surface layer testifying to an intensive annual ventilation of the CIL (Fig. 2b,c). This coincides with positive NAO index during several years in the beginning of the 1990s (Fig. 6). Since 2000, visible and stable difference between DO content in the surface layer and in the CIL has been observed, evidence of an absence of full renovation of the CIL. Before 1999 there were no correlation between oxygen and temperature in the CIL (Fig. 7a), but after 1999 these parameters became correlated. In parallel, the observed increase of salinity gradient above the CIL core in warm years (Fig. $2 \mathrm{~g}$ ) testifies to restricted vertical mixing that may be one of the causes of the absence of the complete CIL renovation.

The decreased oxygen concentration in CIL, up to 50\% in 20002011, compared with 1984-1999 induced a reduction in the oxygen concentration in pycnocline and in the oxygen deficient layer (Fig. 2d), and an upward shift of the hydrogen sulphide boundary (Fig. 2e,f). Interrelations between the oxygen concentration in the CIL and in the oxygen deficient layer as well as with the hydrogen sulphide boundary position were found (Fig. 8). Our results elucidated the mechanism of response of the Black Sea ecosystem to climate change. Changes in the winter weather conditions mainly related to the NAO result in stronger or weaker cooling of the upper layer of the Black Sea waters (Yakushev et al., 2006; Oguz et al., 2006). The changes of the mean winter air temperature over the sea and SST lead to changes of winter CIL formation intensity (Oguz et al., 2006; Oguz and Ediger, 2006; Kazmin et al., 2010) and, therefore, to the oxygen replenishment there. The CIL is analogous to a "battery" holding a "charge" of oxygen that supports the organic matter decay in the water column and the downward diffusive flux of oxygen throughout the year (Yakushev et al., 2008).

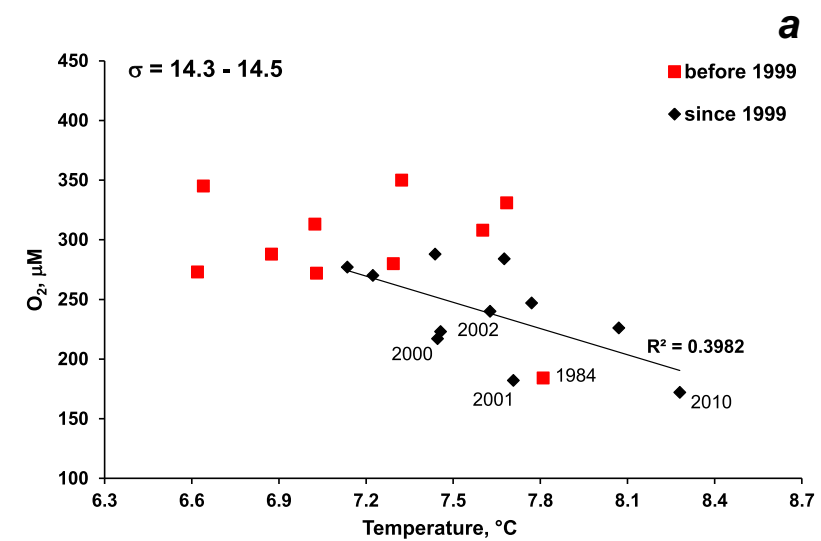

b

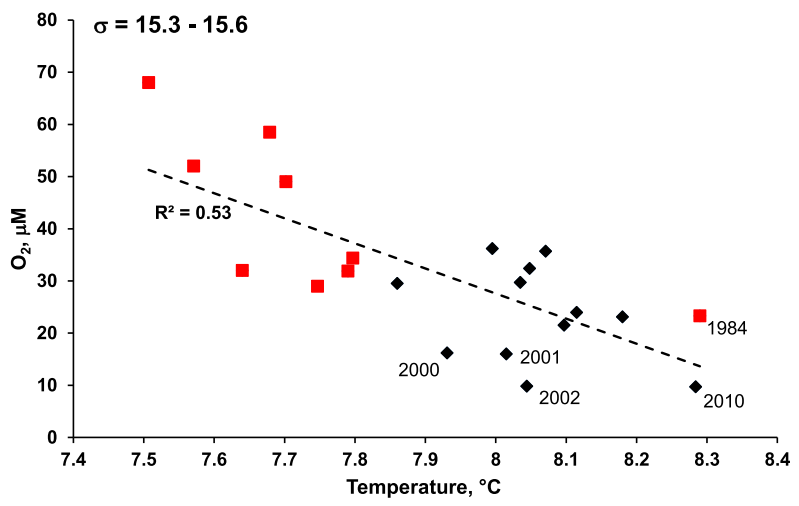

C

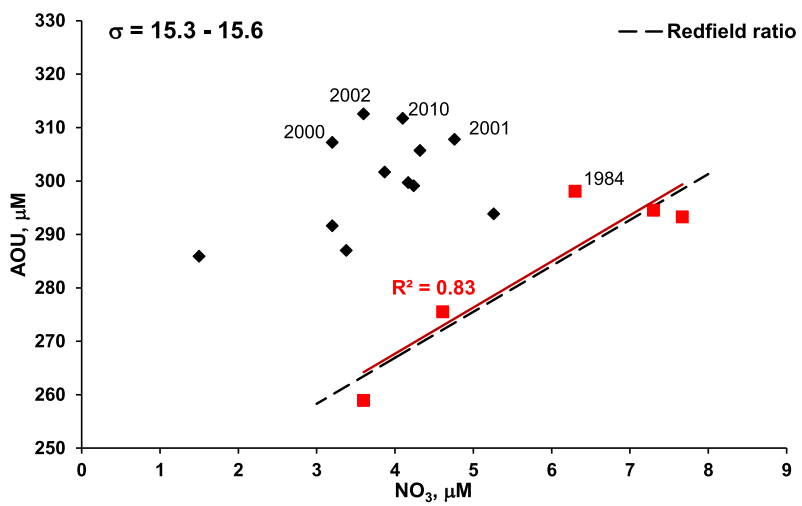

Fig. 7. Oxygen versus temperature in the upper part of the CIL, $\sigma_{\theta}=14.3-14.5 \mathrm{~kg} \mathrm{~m}^{-3}$ (a) and in the middle pycnocline, $\sigma_{\theta}=15.3-15.6 \mathrm{~kg} \mathrm{~m}^{-3}$ (b) and AOU versus nitrate concentration in the middle pycnocline, $\sigma_{\theta}=15.3-15.6 \mathrm{~kg} \mathrm{~m}^{-3}$ (c) in $1984-2010$. Correlation coefficients are shown for periods 1999-2010 (a), 1984-2010 (b) and 1984-1994 (c) 
a

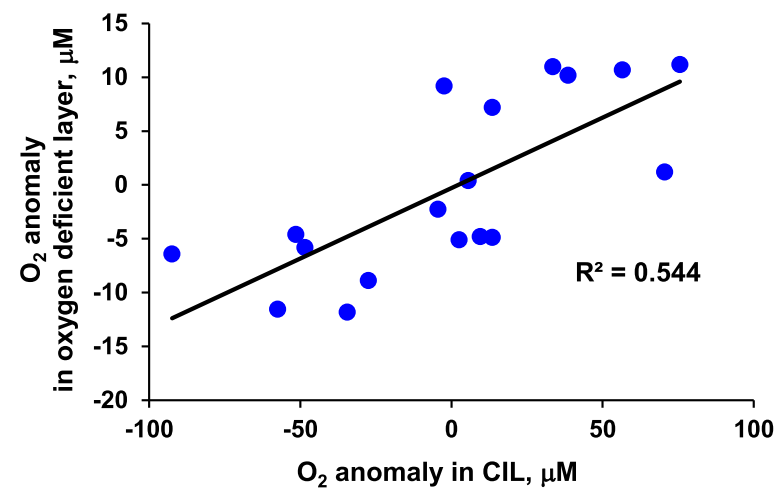

b

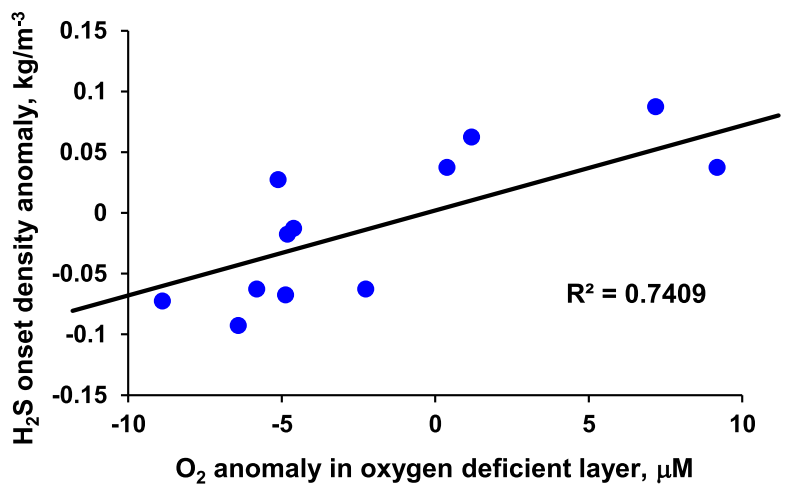

$\boldsymbol{C}$

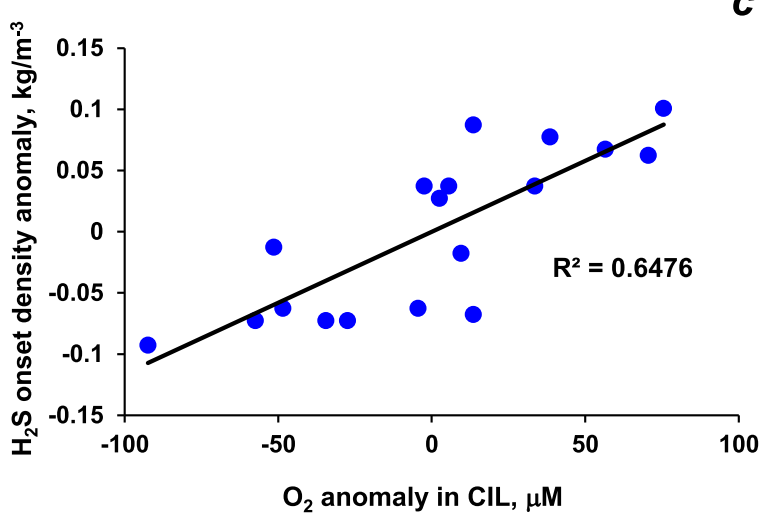

Fig. 8. Correlations of DO concentrations in the CIL and DO in the oxygen deficient layer (a), hydrogen sulphide onset position and DO concentration in oxygen deficient layer (b), hydrogen sulphide onset position and DO concentration in the CIL (c).

The interannual variations of the CIL oxygen renovation underlie the changes of the oxygen deficient layer hydrochemical structure and, in particular, the shifts of the anoxic layer boundary position in the density field. These shifts in the density field correspond to variations of the hydrogen sulphide boundary by about $10-30 \mathrm{~m}$ in the depth field. This could have possibly resulted in decrease or increase of the oxic zone volume up to $10 \%$ (Yakushev et al., 2008).

The cold winters can lead to an increased penetration of the surface DO to the CIL and also to a supply of nutrients from the depths of CIL to the surface layer. This can explain a sudden increase of phosphate in the surface layer up to its concentration in CIL in the cold period in the beginning of 1990s (Fig. 2a,b and 3e). This effect is less detectable in the DIN, because the DIN concentrations in the surface water and CIL are closer. However the difference between these concentrations is smaller in colder periods and larger in the warm periods (Fig. 3d). It is very difficult to see this effect in the silicate because of its high concentrations in the surface layer to the end of 1990s (Yakushev et al., 2010).

The importance of climate forcing for biogeochemical processes in the oxygen-deficient and anoxic basins is consistent with other studies. In particular, a similar mechanism of a dependence of DO on climatic variations was shown by Erlandsson et al. (2006), who demonstrated that about $40 \%$ of the observed oxygen dynamics in a fjord were determined by physical factors connected to the NAO. In recently published modeling results by He et al. (2012) it is emphasized that extreme climatic events are most important to the biogeochemistry of the Black Sea redox zone. There is also evidence that the Black Sea Chlorophyll-a regime can also be triggered by the winter conditions (i.e. in 2001) (McQuatters-Gollop et al., 2008).

\subsubsection{Western and northwestern parts of the Black Sea}

In the $\mathrm{W}$ part of the Black Sea the surface layer winter DO concentrations followed the same decreasing tendency as in the NE part (Fig. 2b). Minimal concentrations were observed in the warmest years, 2001 and 2010. Since no trend was observed for the oxygen saturation in the surface layer (Fig. 2c), the decreasing of DO concentration can be explained only by an increasing temperature (Fig. 2a). The similar decreasing trend was noted and in the NW shelf of the Black Sea with minimal and maximal DO concentrations in the same warm and cold periods, while the absolute winter DO concentration in the surface layer were about $100 \mu \mathrm{M}$ higher than in the NE and W parts (Oguz et al., 2008b; Gomoiu, personnel communication, 2012). This is connected with colder winter temperature of the surface layer in the NW shelf.

DO variability in the CIL in the W Black Sea has the same tendencies as in the NE part of the Sea. In the warm periods (20012002 and 2010) DO concentration decreased to $200 \mu \mathrm{M}(60 \%$ of saturation) and raised to about 270-290 $\mu \mathrm{M}(80 \%)$ in the cold period (2004-2008). As in the NE Black Sea, DO concentrations in the CIL in the W Black Sea in 2001-2010 hadn't reached $300 \mu \mathrm{M}$ (90\%) which confirms that the CIL renovation after 2000 was weaker than in the 1990s.

\subsection{Anthropogenic forcing and nutrients regime}

\subsubsection{Northeastern and western parts of the Black Sea}

During the last two decades, the trophic status of the surface layer of the NE Black Sea has significantly changed with a relatively stable decrease in inorganic phosphorus since 1995, and in nitrogen species since 2000 . No clear trend was observed for silica (Fig. 4ac). Nutrient variability in the $\mathrm{W}$ part of the Black Sea shows practically no trends for the winter season for the period 2001-2010, in a similar way as for the NE part of Sea (Fig. $4 a-c)$. The W Black Sea is characterized by the same level of DIN and phosphate concentrations and about two times higher silicate concentration than the NE Black Sea (Fig. 4a-c) (Shtereva et al., 2003; Krastev et al., 2006, 2010; Moncheva et al., 2010). At the same time a clear decreasing trend for silicate was recorded in the $\mathrm{W}$ Black Sea in the spring season in 2001-2010 (Table 2). In contrast, in the NE Black Sea no significant differences between the spring and summer average concentrations of DIN and phosphate and no interannual tendencies for these seasons were found. The larger range of nutrient variability in the $\mathrm{W}$ part compared to the NE Black Sea is mainly attributed to the rivers input influence (Danube, Dniester, Dniepr, Southern Bug and Bulgarian rivers) and the width of the shelf zone. A more pronounced decreasing trend for silicate was observed in spring in the coastal zone of W Black Sea (Krastev et al., 2006, 2010; Moncheva et al., 2010), which probably reflects the diminished supply through the rivers since 2007. In the NE coastal zone, silicate 
concentration has also significantly decreased since 2007 (Chasovnikov et al., 2012). The depletion of silica in the surface waters has been found to have an important impact on phytoplankton species composition: shifts from siliceous (mainly diatoms) to non-siliceous (cocolithophorides and flagellates) species was reported (Petrova-Karadjova, 1984; Nesterova, 1987; Moncheva and Krastev, 1997; Bodeanu et al., 2002; Mikaelyan et al., 2013) and changes in their seasonal dynamics were observed (Velikova et al., 1999). A detailed analysis of the influence of these changes on the biological processes in the Black Sea was previously presented by different authors (Yilmaz et al., 2006; BSC, 2008; Mikaelyan et al., 2013).

\subsubsection{Peculiarities of the northwestern shelf nutrient regime}

The data from the NW shelf (Cociasu et al., 1996; Parr et al., 2005; BSC, 2008; Yakushev et al., 2010; Oguz and Velikova, 2010) reveal similar general decreasing trends for phosphate and an absence of a trend for silicate in the surface water, as observed in the NE Black Sea during the studied period. However, the concentrations in the NW Shelf region are 3-4 times higher. In the first half of the 1990s, an increase in the phosphate concentration was observed in both the NE and NW parts of the Black Sea (Fig. 3e, Oguz et al., 2008b), while phosphate input from Danube river decreased significantly in 1992. Such an increase can be caused in the NW part by a release from the polluted sediments (Oguz et al., 2008b) but in the Black Sea Proper it can be connected with an increased supply of nutrient from the deeper layers during intensive mixing in the cold winters observed these years (Figs. 2a and 3e). After 1996 a decreasing trend of phosphate was rather stable in both the regions. DIN concentrations increased during the decade 2000-2010 up to $8 \mu \mathrm{M}$ in the NW part but considerably decreased in the NE part of the sea. These typical for the NW region high concentrations (even compared to the W Black Sea) and a different character of variability are connected with the Danube River. That is why the NW shelf chemical regime differs from the nutrient regime of the Black Sea Proper.

In the regions subjected to the influence of the Danube River, the $\mathrm{N} / \mathrm{P}$ ratio was 11.7 in the 1970 s and $22-23$ in 1988-1992 (Cociasu et al., 1996). Due to a decrease in the phosphate input, this ratio increased in 1995 to as high as 100. Since 1996, it has decreased significantly (e.g. down to 20 in 2000) due to the diminishing annual input of nitrate from the Danube River from 770 thousand tons in 1991 to 108.9 thousand tons in 2000 measured at Sulina (Yilmaz et al., 2006). Having in mind the N/P ratio in 1980s-1990s, the NW shelf region could be characterized as an area of phosphorus limitation of primary production, however, the tests completed in 2001 showed no clear P-limitation on the shelf (Yilmaz et al., 2006). In the NE Black Sea, N-limitation was observed in 2002-2008 (Fig. 5). This significantly affects the Sea plankton community structure (Mikaelyan et al., 2013). An additional factor of the ecosystem perturbations and appearance of the ecological regime shifts in the Black Sea can be connected with the food chain and trophic cascading (Daskalov et al., 2007).

\subsection{Eutrophication vs. climate}

Eutrophication is another factor that might affect the interannual dynamics of the Black Sea hydrogen sulphide layer and its boundary position beside the climatic factors. The main sink for oxygen is the respiration and the decomposition of dissolved and particulate organic matter (Sorokin, 2002). Variability in the flux of particulate organic carbon (export production) is connected with the nutrient concentration regime and is itself dependent on the food web functional structure. The 1970s-1980s was a period of increased nutrient levels in the Black Sea, resulting in lower oxygen concentrations in the CIL (Konovalov and Murray, 2001).
However, the analysis was not able to reveal a detectable interannual variability of the surface layer average winter nutrient concentrations after 2001 both in the NE and W parts of the Sea (Fig. $4 a-c$ ). Nutrient concentrations in the CIL in the NE Black Sea also have not changed significantly during the last two decades (Fig. 3d-f). The maximum nitrate concentration in the NE Black Sea, $11 \mu \mathrm{M}$, was observed in 1991, and in 1999-2010 it remained in the range of $3-5 \mu \mathrm{M}$.

On the basis of our data, we plotted correlations of apparent oxygen utilization (AOU) vs. nitrate maximum and DO vs. temperature in the pycnocline (Fig. $7 \mathrm{~b}, \mathrm{c}$ ). Our estimates for temperature, DO, AOU and nitrate corresponded well to those in (Konovalov and Murray, 2001; Konovalov et al., 2005) considered for the period before 2003. With our plot it was possible to compare the periods 1984-1998 and 1999-2010. It can be shown that temperature and oxygen remained correlated in both the periods, while temperature increased significantly in 1999-2010 compared with 1984-1998. At the same time correlation between concentrations of nitrate and AOU changed significantly (Fig. 7c). It was close to Redfield from 1984 to 1998 which allowed (Konovalov et al., 2005) to conclude that the oxygen regime is determined by the flux of organic matter. But in the period 1999-2010 this relation changed (Fig. 7c). The highest values of AOU are attributed to the warmest years at enough low nitrate concentration in the pycnocline. Therefore the main factor affecting the oxygen regime and the position of the hydrogen sulphide boundary after 1999 are the physical (climatic) forcing. A decoupling of nutrient and oxygen dynamics in the last two decades indicates an absence of significant cultural eutrophication.

The process of production of gaseous nitrogen through denitrification and anammox is a well known feature of water basins with oxygen-deficient conditions, such as the Black Sea. The results of modeling showed that this loss of gaseous nitrogen must be compensated by nitrogen fixation to keep the nitrogen budget balance. (Yakushev et al., 2007b).

Denitrification and anammox were measured in the Black Sea during 1970s-1990s (Murray et al., 2003; Kuypers et al., 2003), yet nitrogen fixation was not observed in this period. On the other hand, nitrogen fixation was observed in 1950s prior the beginning of the period of intensive cultural eutrophication (Pshenin, 1963). Probably this absence of nitrogen fixation in 1970s-1990s can be explained by an intensive supply of the bound nitrogen species in these years, that nitrogen was not a limiting element, and the conditions did not favor nitrogen fixation. At the beginning of 2000s the concentrations of nitrate decreased considerably and nitrogen became a limiting element (Yilmaz et al., 2006). The low $\mathrm{N} / \mathrm{P}$ ratio observed in different areas of the Black Sea testified to nitrogen-limited phototrophic production which would typically require nitrogen-fixation under the conditions of normal ecosystem functioning to sustain the naturally high productivity of this sea. Nitrogen fixation was again measured in the central Black Sea in 2003 (McCarthy et al., 2007) which was well related with the notable decrease of land-based supply of this nutrient during the last decade. This re-appearance of nitrogen fixation in the sea can be one of indicators of the Black Sea ecosystem recovery.

Undoubtedly, the significant anthropogenic nutrient loads of previous periods (1970s-1980s) have substantially decreased in the Black Sea region nowadays. The recently published Black Sea Commission Report (Oguz et al., 2008a) concludes on the advancement of the process of revival of the Black Sea bringing numerous evidences of the improvement of the pelagic ecosystem state of the Sea. These are reduced nutrient inputs and less frequent algal blooms, lower phytoplankton biomass, recovery of some macroalgal populations, increasing plankton diversity, decreasing pressure imposed by the proliferation of gelatinous and other 
opportunistic species, and re-appearance of some native trophic mesozooplankton, benthic and pelagic species. The results of this study support the previous findings of positive signs of recovery of the Black Sea ecosystem, and show that the role of climate forcing in the biogeochemical regime becomes dominating.

\section{Conclusions}

The Black Sea Proper, a chemically homogenous area separated by a Rim current, is characterized by specific oxygen and nutrient regimes that differ from that of the NW shelf region. These oxygen and nutrient regimes are the main factors that changed during the last several decades.

- Climate variation has increased surface temperature, stratification and therefore there has been a decrease in winter mixing.

- Anthropogenic nutrient loads in the region have significantly decreased during the last $10-15$ years compared to the period of progressive eutrophication (1970s and 1980s).

The biogeochemical regime of the Black Sea Proper oxygenated layer has notably changed since 1999:

- After 1999, DO concentration in the CIL decreased by $20 \%$ while the concentrations in the surface layer changed very little, therefore the CIL waters were not fully replenished during the winters of the last decade.

- Oxygen and nutrient dynamics in the middle pycnocline have been decoupled.

- Elevation of the hydrogen sulphide boundary by about 10-30 m has been observed.

- Nutrient concentrations in the upper layer decreased in line with the decrease in anthropogenic eutrophication.

Currently physical (climatic) forcing has become a dominant affecting factor of the Sea oxygen and nutrient regime:

- Warm periods (series of warm winters) lead to a decrease of oxygen in the CIL, an elevation of the hydrogen sulphide boundary and a decrease of nutrient in the surface layer.

- Cold periods (series of cold winters) lead to an increase of oxygen in the CIL, deepening of the hydrogen sulphide boundary and increase of nutrient in the surface layer.

\section{Acknowledgments}

The authors thank Violeta Velikova and Alice Newton for the discussions of the results received. The work was partly supported by the Russian Federal Program "The World Ocean" and the EC FP6 “SESAME”, FP7 “PERSEUS”.

\section{References}

Akima, H., 1978. A method of bivariate interpolation and smooth surface fitting for irregularly distributed data points. ACM Trans. Math. Software 4, 148-159.

Bodeanu, N., Boicenco, L., Popa, L., Andrei, C., 2002. Evolution of the phytoplankton and algal blooms for the Romanian area of the Black Sea at the limit between XXth and XXIst centuries. In: Yilmaz, A. (Ed.), Oceanography of Eastern Mediterranean and Black Sea. Tubitak, Ankara, pp. 734-739.

Bordovskiy, O.K., Chernyakova, A.M. (Eds.), 1992. Modern Methods of the Ocean Hydrochemical Investigations. P.P.Shirshov Institute of Oceanology, Moscow, p. 200 (In Russian).

BSC, 2008. State of the Environment of the Black Sea 2001-2006/7, 2008. Black Sea Commission Publications, Istanbul, Turkey, p. 448.

Chasovnikov, V.K., Yakushev, E.V., Menshikova, N.M., Chzhu, V.P., Kuprikova, N.L. 2011. Variability of Nutrients in the Coastal Zone of the Black Sea. In: Esin, N.V. (Ed.), Collected Articles of IO RAN "Resent Studies of the Black Sea". Nauchnyi Mir, Moscow, pp. 255-268 (In Russian).
Cociasu, A., Dorogan, L., Humborg, C., Popa, L., 1996. Long term ecological changes in Romanian coastal waters of the Black Sea. Mar. Pollut. Bull. 32, 32-38.

daNUbs, 2005. Nutrient Management in the Danube Basin and its Impact on the Black Sea. Final Report, p. 69. Available at: <http://danubs.tuwien.ac.at $>$.

Daskalov, G.M., Grishin, A.N., Rodionov, S., Mihneva, V., 2007. Trophic cascades triggered by overfishing reveal possible mechanisms of ecosystem regime shifts. Proc. Natl. Acad. Sci. U S A. 104 (25), 10518-10523.

Erlandsson, C.P., Stigebrandt, A., Arneborg, L., 2006. The sensitivity of minimum oxygen concentrations in a fjord to changes in biotic and abiotic external forcing. Limnol. Oceanogr. 51, 631-638.

Gomoiu, M.T., Oaie, G., Secrieru, D., Teaca, A., Begun, T., Opreau, P., Vasiliu, D., Muresan, M., Caraus, I., Boicenco, L., Lazar, L., 2012. Oxygen and biotic assemblage patterns of distribution in the NW Black Sea sector directly influenced by the Danube River discharge. In: Proceedings of the HYPOX Final Meeting, INGV, Rome, Italy.

Grashoff, K., Kremling, K., Ehrhard, M., 1999. Methods of Seawater Analysis. WILEYVCH, Weinheim-NewYork-Chichester-Brisbane-Singapore-Toronto, p. 420.

Gregg, M.C., Yakushev, E., 2005. Surface ventilation of the Black Sea's cold intermediate layer in the middle of the western gyre. Geophys. Res. Lett. 32, L03604.

Hansen, H.P., 1999. Determination of oxygen. In: Grashoff, K., et al. (Eds.), Methods of Seawater Analysis. WILEY-VC, Weinheim-NewYork, pp. 75-90.

He, Yu., Stanev, E.V., Yakushev, E., Staneva, J., 2012. Black Sea biogeochemistry: response to decadal atmospheric variability during 1960-2000 inferred from numerical modeling. Mar. Environ. Res. 77, 90-102.

Kazmin, A.S., Zatsepin, A.G., 2007. Long-term variability of surface temperature in the Black Sea, and its connection with the large-scale atmospheric forcing J. Mar. Syst. 68, 293-301.

Kazmin, A.S., Zatsepin, A.G., Kontoyiannis, H., 2010. Comparative analysis of the long-term variability of winter surface temperature in the Black and Aegean Seas during 1982-2004 associated with the large-scale atmospheric forcing. Int. J. Climatol. 30, 1349-1359.

Konovalov, S.K., Murray, J.W., 2001. Variations in the chemistry of the Black Sea on a time scale of decades. J. Mar. Sci. 31, 217-243.

Konovalov, S.K., Murray, J.W., Luther, G.W., 2005. Basic processes of Black Sea biogeochemistry. Oceanography 18, 24-35.

Kosarev, A.N., Kostianoy, A.G., 2008. Introduction. In: Kostyanoy, A.G., Kosarev, A.N. (Eds.), The Handbook of Environmental Chemistry, The Black Sea Environment, Vol. 5. Springer-Verlag, Berlin-Heidelberg-New York-Tokyo, pp. 1-10.

Krastev, A., Shtereva, G., Hristova, O., Dzhurova, B., 2006. Nutrients in the Western Black Sea area - spatial and vertical distribution. In: Proceeding of 1-st Black Sea Conference, "Black Sea Ecosystem 2005 and beyond”. Istanbul, pp. 93-105.

Krastev, A., Shtereva, G., Hristova, O., Dzhurova, B., 2010. Vertical hydrochemical structure of the western Black Sea area in 2007-2008 period. Rapp. Comm. Int. Mer. Medit. 39, 271. Venice, Italy.

Krivosheya, V.G., Ovchinnikov, I.M., Skirta, A.Yu, 2002. Intraannual variability of the cold intermediate layer of the Black Sea. In: Zatsepin, A.G., Flint, M.V. (Eds.), Complex Investigation of the Northeastern Black Sea. Nauka, Moscow, pp. 27-39.

Kuypers, M.M.M., Sliekers, A.O., Lavik, G., Schmid, M., Jorgensen, B.B., Kuenen, J.G. Sinnenghe Damste, J.S., Strous, M., Jetten, M.S.M., 2003. Anaerobic ammonium oxidation by anammox bacteria in the Black Sea. Nature 422, 608-611.

McCarthy, J.J., Yilmaz, A., Coban-Yildiz, Y., Nevins, J.L., 2007. Nitrogen cycling in the offshore waters of the Black Sea. Estuar. Coast. Shelf Sci. 74, 493-514.

McQuatters-Gollop, A., Mee, L.D., Ritsos, D.E., Shapiro, G.I., 2008. Non-linearities, regime shifts and recovery: the recent influence of climate on Black Sea chlorophyll. J. Mar. Syst. 74, 649-658.

Mikaelyan, A.S., Zatsepin, A.G., Chasovnikov, V.K., 2013. Long-term changes in nutrient supply of phytoplankton growth in the Black Sea. J. Mar. Syst. 117-118, 53-64.

Moncheva, S., Krastev, A., 1997. Some aspect of phytoplankton long-term alterations off Bulgarian Black Sea shelf. In: Oszoy, E., Mikhaelian, A. (Eds.), Sensitivity to Change: Black Sea, Baltic Sea and North Sea, NATO ASI Series, Environment, vol. 27. Kluwer Academic Publishers, London, pp. 79-94.

Moncheva, S., Shtereva, G., Stefanova, K., Slabakova, N., Krastev, A., Hristova, O. Djurova, B., Slabakova, V., Mavrodieva, R., 2010. On the resent features of chemical and biological regimes in the western Black Sea ecosystem (2007). In: Kolev, P., Kyulevchelef, S., Yosifov, K. (Eds.), Proceedings of Tenth International Conference of Marine Sciences and Technologies "Black Sea'2010”, pp. 288296. Varna, Bulgaria.

Murray, J.W., Codispoti, L.A., Friederich, G.E., 1995. Oxidation-reduction environments: the suboxic zone in the Black Sea. In: Huang, C.P., O'Melia, C.R., Morgan, J.J. (Eds.), Aquatic Chemistry: Interfacial and Interspecies Processes. ACS Advances in Chemistry Series, pp. 157-176.

Murray, J.W., Fuchsman, C., Kirpatrick, J., Paul, B., Konovalov, S.K., Callahan, A., 2003. Nitrogen reactions in the suboxic zone of the Black Sea. Oceanography 18, 36-47.

Nesterova, D.A., 1987. Some features of succession of phytoplankton in the northwestern Black Sea. Hydrobiologycheskyi Zhurnal 23, 16-21 (In Russian).

Oguz, T., Dippner, J.W., Kaymaz, Z., 2006. Climate regulation of the Black Sea hydrometeorological and ecological properties at interannual-to-decadal time scales. J. Mar. Syst. 60, 235-248.

Oguz, T., Ediger, D., 2006. Comparison of in situ and satellite-derived chlorophyl pigment concentrations, and impact of phytoplankton bloom on the suboxic layer structure in the western Black Sea during May-June 2001. Deep-Sea Res. II $53,1923-1933$. 
Oguz, T., Kideys, A., Velikova, V., 2008a. A overall assessment of the present state of the Black Sea ecosystem. In: BSC, 2008. State of the Environment of the Black Sea 2001-2006/7. Black Sea Commission Publications 2008-3, pp. 417-446. Istanbul, Turkey.

Oguz, T., Velikova, V., Cociasu, A., Korshenko, A., 2008b. The state of eutrophication. In: BSC, 2008. State of the Environment of the Black Sea 2001-2006/7. Black Sea Commission Publications 2008-3, pp. 83-113. Istanbul, Turkey.

Oguz, T., Velikova, V., 2010. Abrupt transition of the northwestern Black Sea shelf ecosystem from a eutrophic to an alternative pristine state. Mar. Ecol. Progr. Ser. 405, 231-242.

Ozsoy, E., Unluata, U., 1997. Oceanography of the Black Sea: a review of some resent results. Earth Sci. Rev. 42 (4), 231-272.

Parr, W., Volovik, Y., Nixon, S., Lipan, I., 2005. Improving the Understanding of the Danube River Impact on the Status of the Black Sea. In: Draft Report to the Black Sea - Danube Technical Working Group, p. 109.

Petrova-Karadjova, V., 1984. Changes in planktonic flora in Bulgarian Black Sea waters under the influence of eutrophication. In: Proceedings of IFR-Varna, vol. 21, pp. 105-112.

Podymov, O.I., 2008. Use of a problem-oriented database for statistical analysis of the hydrochemical characteristics of the redox layer of the Black Sea. Oceanology 48, 656-663.

Pshenin, L.N., 1963. Distribution and ecology of Azotobacter in the Black Sea. In Oppenheimer, C.H. (Ed.), Symposium on Marine Microbiology. Charles C. Thomas, Publisher, Springfield, Ill, pp. 383-391.

Piotukh, V.B., Zatsepin, A.G., Kazmin, A.S., Yakubenko, V.G., 2011. Impact of the winter cooling on the variability of the thermohaline characteristics of the active layer in the Black Sea. Oceanology 51 (2), 221-230.

Shapiro, G.I., Aleynik, D.L., Mee, L.D., 2010. Long term trends in the sea surface temperature of the Black Sea. Ocean Sci. 6, 491-501.

Shtereva, G. Krastev, A., Hristova, O., 2003. Vertical distribution of nutrients in the western black sea area (summer 1998-2002). In: Yulmaz, A. (Ed.), Proceedings of Second International Conference "Oceanography of Eastern Mediterranean and Black Sea”, pp. 438-442. Ankara, Turkey.

Sorokin, Yu.I., 2002. The Black Sea. Ecology and Oceanography. Backhuys Publishers, Leiden, p. 875 .
Velikova, V., Moncheva, S., Petrova, D., 1999. Phytoplankton dynamics and Red Tides (1987-1997) in the Bulgarian Black Sea. Water Sci. Technol. 39 (8), 27-36.

Vinogradov, M.E., Nalbandov, Yu.P., 1990. Dependence of physical, chemical and biological parameters in pelagic ecosystem of the Black Sea upon the water density. Oceanology 30, 769-777.

Volkov, I.I., Kontar', E.A., Lukashev, Yu.F., Neretin, L.N., Nyffeler, F., Rozanov, A.G., 1997. Upper boundary of the hydrogen sulphide and the nature of the Nepheloid Redox Layer in the waters of the Caucasian Slope of the Black Sea. Geochem. Int. 6, 618-629.

Yakushev, E.V., Podymov, O.I., Chasovnikov, V.K., 2005. Seasonal changes in hydrochemical structure of the Black Sea redox zone. Oceanography 18, 44-51.

Yakushev, E.V., Chasovnikov, V.K. Debolskaya, E.I. Egorov, A.V. Makkaveev, P.N., Pakhomova, S.V., Podymov, O.I., Yakubenko, V.G., 2006. The northeastern Black Sea redox zone: hydrochemical structure and its temporal variability. Deep Sea Res. II 53, 1764-1786.

Yakushev, E.V., Pollehne, F., Jost, G., Umlauf, L., Kuznetsov, I., Schneider, B., 2007a. Analysis of the water column oxic/anoxic interface in the Black and Baltic seas with a Redox-Layer Model. Mar. Chem. 107, 388-410.

Yakushev, E.V., Arkhipkin, V.S., Antipova, E.A., Kovaleva, I.N., Chasovnikov, V.K., Podymov, O.I., 2007b. Seasonal and interannual variability of hydrology and nutrients in the Northeastern Black Sea. Chem. Ecol. 23, 29-41.

Yakushev, E.V., Chasovnikov, V.K., Murray, J.W., Pakhomova, S.V., Podymov, O.I. Stunzhas, P.A., 2008. Vertical hydrochemical structure of the Black Sea. In: Kostyanoy, A.G., Kosarev, A.N. (Eds.), The Handbook of Environmental Chemistry, The Black Sea Environment, vol. 5. Springer-Verlag, Berlin-HeidelbergNew York-Tokyo, pp. 277-307.

Yakushev, E., Chelysheva, M., Podymov, O., Velikova, V., Chasovnikov, V., Belokopytov, V., 2010. On the recent decadal changes of the Black Sea nutrient regime and oxic/anoxic boundary position. In: Briand, F. (Ed.), CIESM, 2010. Climate Forcing and Its Impacts on the Black Sea Marine Biota. N 39 in CIESM Workshop Monographs, pp. 25-34. Monaco.

Yilmaz, A., Coban-Yildiz, Y., Telli-Karakoc, F., Bologa, A., 2006. Surface and midwater sources of organic carbon by photo- and chemoautotrophic production in the Black Sea. Deep-Sea Res. II 53, 1988-2004. 